\title{
Gastrointestinal Tract Heterotopic Pancreas: Asymptomatic Pathology?
}

\author{
Amir Farah ${ }^{a}$, Subhi Mansoura ${ }^{a}$, Safi Khuria, b, c
}

\section{To the Editor}

Congenital anomalies involving the pancreas can be categorized into fusion anomalies, duplication anomalies and migration anomalies, with heterotopic pancreas belonging to the latter [1]. Heterotopic pancreas, firstly described by Jean Schultz in 1727 and histopathologically confirmed by Klob in 1859 [2], is also known as ectopic, aberrant or accessory pancreas, as well as pancreatic rest, choristoma and adenomyoma [3]. It is defined as the presence of pancreatic tissue away from the usual anatomical location of the pancreas, without vascular or ductal continuity. This anatomical anomaly is similar to the original pancreas in terms of genetic make-up and physiological function. Several theories regarding the pathogenesis of heterotopic pancreas were suggested, with the "misplacement" theory being the most accepted one. According to the aforementioned theory, pancreatic tissue deposits are dropped away from the main pancreas, into the developing gastrointestinal tract [4]. Although the incidence rate of said anomaly is considered low, the precise rate is unknown, with autopsy results demonstrating a prevalence rate of $0.5-13.7 \%$ [5]. Heterotopic pancreas can also be found incidentally following stomach resection and other upper gastrointestinal surgeries in $0.9 \%$ and $0.2 \%$, respectively $[6,7]$. It is more common in males than in females with a male to female ratio of $3: 1$, most often discovered during the fifth to sixth decades of life [8].

Heterotopic pancreas can be found at any level of the gastrointestinal tract, with more than $90 \%$ of cases diagnosed in the stomach, duodenum and proximal jejunum [9]. The duodenum, mostly the descending part, is the most frequent site of involvement $(27.7 \%)$, followed by the stomach (greater curve) and proximal jejunum (usually at the Treitz ligament level) in $25.5 \%$ and $15.9 \%$, respectively $[4,7,10]$. Other less common reported gastrointestinal tract sites include ileum $(2.8 \%)$,

Manuscript submitted January 17, 2021, accepted February 4, 2021

Published online February 19, 2021

${ }^{a}$ General Surgery Department, Rambam Health Care Campus, Haifa, Israel bHPB and Surgical Oncology Unit, Rambam Health Care Campus, Haifa, Israel

${ }^{\mathrm{c} C o r r e s p o n d i n g ~ A u t h o r: ~ S a f i ~ K h u r i, ~ H P B ~ a n d ~ S u r g i c a l ~ O n c o l o g y ~ U n i t, ~ R a m-~}$ bam Health Care Campus, Haaleya Hashneya, Haifa, Israel.

Email: S_khuri@rambam.health.gov.il

doi: https://doi.org/10.14740/gr1363
Meckel's diverticulum (5.3\%), colon, esophagus, omentum, spleen, liver and the mesentery. only few cases, published in the English literature as case reports, discuss heterotopic pancreas at the esophagus, mainly the distal part [11]. Moreover, up to 11 cases of mesenteric heterotopic pancreas were reported. Some extremely rare locations of heterotopic pancreas reported include lungs, mediastinum and the gallbladder [12]. So far, less than 40 cases of gallbladder heterotopic pancreas have been reported worldwide. Due to the fact that only a few case reports of heterotopic pancreas at the gallbladder have been reported, the clinical presentation and radiological findings are ill defined.

Grossly, heterotopic pancreas along the gastrointestinal tract is firm subepithelial lesions, lobular in shape with well defined interface with the nearby structures [13]. Histologically, heterotopic pancreas is a true pancreatic gland that includes the same components as for the native pancreas, and categorized into three types according to its component [14]: type I (all types of pancreatic tissue), type II (only pancreatic ducts) and type III (only pancreatic acini). Due to the previously mentioned fact, any pathology affects the native pancreas, such as inflammation or neoplastic transformation, can develop as well in the heterotopic counterpart. The risk for malignant transformation is extremely rare, and can arise from either exocrine or ductal components.

Reviewing the current English literature reveals very limited number of studies, mainly small volume retrospective and case series studies, limited to single center experience regarding heterotopic pancreas. The majority of the data about this unique anomaly is published as case reports.

Although regarded in English literature as an incidental radiological/operative finding, clinical presentation of heterotopic pancreas differs from one study to the other, and depends on several parameters such as patients' age, gastrointestinal tract location, lesion size, timing of surgery and mucosal involvement. In their large series studies, Zhang et al [15] and Betzler et al [16] reported that almost $85 \%$ of heterotopic pancreas cases were diagnosed incidentally. On the other hand, heterotopic pancreas was symptomatic in $35 \%$ and $100 \%$ of patients in other studies [17-19], respectively. The most common presenting symptom in the previously mentioned studies was abdominal pain (23-50\%). Other reported symptoms were nausea and vomiting (27\%), weight loss (18\%) and upper gastrointestinal hemorrhage (13\%).

Patients' age as a parameter for symptoms was reported by Persano et al [20]. In his study, which included 14 pediatric 
Table 1. Summary of the Findings of the Relevant Studies

\begin{tabular}{llll}
\hline Study & Number of patients & Most common GIT location & Percentage of symptomatic patients \\
\hline Zhang et al, 2016 [15] & 184 & Stomach & $14.10 \%$ \\
Betzler et al, 2017 [16] & 67 & Duodenum (only) & $18.40 \%$ \\
Chen et al, 2008 [18] & 39 & Stomach & $38 \%$ \\
Li et al, 2018 [19] & 132 & Stomach (only) & $100 \%$ \\
Persano et al, 2019 [20] & 14 & Meckel's diverticulum & $50 \%$ \\
Bromberg et al, 2010 [5] & 18 & Stomach & $22 \%$ \\
Armstrong et al, 1981 [21] & 34 & Stomach & $38 \%$ \\
Shi et al, 2002 [24] & 7 & Duodenum & $100 \%$ \\
Jun et al, 2017 [25] & 165 & Stomach & $59 \%$ \\
\hline
\end{tabular}

GIT: gastrointestinal tract.

patients, seven patients $(50 \%)$ were symptomatic and the rest were asymptomatic. Older patients ( 9 years and 5 months) with heterotopic pancreas were more symptomatic than younger patients ( 2 years and 9 months). In the symptomatic subgroup, the most common presenting symptoms were melena and recurrent abdominal pain. In regard to timing of surgery, heterotopic pancreas was more frequently found in patients who underwent emergency surgery than elective surgery ( 9 vs. 5 , respectively).

In other small series studies [5, 21], including 18 and 34 patients, only $22 \%$ and $38 \%$ of patients with heterotopic pancreas, respectively, were symptomatic. A firm causal relationship to symptoms was confirmed as symptoms disappeared completely following surgery. In the aforementioned study [21], there was a direct correlation between the presence of symptoms and the size of the lesion, with lesions greater than $1.5 \mathrm{~cm}$ in diameter being more symptomatic. Another association to mucosal layer involvement was reported in the same study.

Although the previous study reported a firm relationship between heterotopic pancreas and symptoms, Dolan et al [22] had difficulty constructing a theory linking heterotopic pancreas and symptoms.

Edward et al [23] reported a retrospective study including 37 patients with heterotopic pancreas, most of them were adult $(84 \%)$ males $(58 \%)$; and the majority of the lesions were in the upper gastrointestinal tract (stomach and duodenum). The study found that lesions located in the stomach and duodenum were more symptomatic; and lesions with mucosal layer involvement in the form of ulceration and large size were also more symptomatic. Similar results as for Edward et al, in regard to location, were reported in the study by Wei et al [7], which included 11 patients with heterotopic pancreas located only at the stomach and duodenum. All patients were symptomatic, with chronic abdominal pain being the most common. As mentioned previously, in one study [15] discussing heterotopic pancreas of the stomach solely, all patients were symptomatic, with epigastric pain being the most common complaint. The same figures were reported by Shi et al [24], where all patients diagnosed with heterotopic pancreas were symptomatic, the most common of which was abdominal pain.

A positive correlation between size and location of lesions and symptomatic heterotopic pancreas were also demonstrated by Jun et al [25]. In this large series study (165 patients), most patients were symptomatic (59\%).

The old claim persisting over the years throughout the English literature, stating that heterotopic pancreas is mainly asymptomatic should be questioned, as demonstrated herein. Heterotopic pancreas could be symptomatic, with wide range of symptoms occurring in $15-100 \%$ of cases (Table $1[5,15$, $16,18-21,24,25])$. This depends on several factors reported previously. Parameters such as older age, larger lesion diameter size (mostly more than $1.5 \mathrm{~cm}$ in diameter), upper gastrointestinal tract location (stomach and duodenum) and mucosal layer involvement were more associated with the presence of symptoms. Due to lack of studies in the English literature, multi-centric high-volume studies are encouraged.

\section{Acknowledgments}

None to declare.

\section{Financial Disclosure}

Authors have no financial disclosure to report.

\section{Conflict of Interest}

The authors declare that they have no conflict of interest concerning this article.

\section{Informed Consent}

Not applicable.

\section{Author Contributions}

Safi Khuri designed the research; Ameer Farah and Subhi 
Mansour collected and analyzed data. Safi Khuri wrote and approved the final paper.

\section{Data Availability}

The authors declare that data supporting the findings of this study are available within the article.

\section{References}

1. Borghei P, Sokhandon F, Shirkhoda A, Morgan DE. Anomalies, anatomic variants, and sources of diagnostic pitfalls in pancreatic imaging. Radiology. 2013;266(1):28-36.

2. Gucer H, Bagci P, Coskunoglu EZ, Karadag C. Heterotopic pancreatic tissue located in the gallbladder wall. A case report. JOP. 2011;12(2):152-154.

3. Jiang LX, Xu J, Wang XW, Zhou FR, Gao W, Yu GH, Lv $\mathrm{ZC}$, et al. Gastric outlet obstruction caused by heterotopic pancreas: A case report and a quick review. World J Gastroenterol. 2008;14(43):6757-6759.

4. Kim DW, Kim JH, Park SH, Lee JS, Hong SM, Kim M, Ha HK. Heterotopic pancreas of the jejunum: associations between CT and pathology features. Abdom Imaging. 2015;40(1):38-45.

5. Bromberg SH, Camilo Neto C, Borges AF, Franco MI, Franca LC, Yamaguchi N. Pancreatic heterotopias: clinicopathological analysis of 18 patients. Rev Col Bras Cir. 2010;37(6):413-419.

6. Kung JW, Brown A, Kruskal JB, Goldsmith JD, Pedrosa I. Heterotopic pancreas: typical and atypical imaging findings. Clin Radiol. 2010;65(5):403-407.

7. Wei R, Wang QB, Chen QH, Liu JS, Zhang B. Upper gastrointestinal tract heterotopic pancreas: findings from $\mathrm{CT}$ and endoscopic imaging with histopathologic correlation. Clin Imaging. 2011;35(5):353-359.

8. Yuan Z, Chen J, Zheng Q, Huang XY, Yang Z, Tang J. Heterotopic pancreas in the gastrointestinal tract. World J Gastroenterol. 2009;15(29):3701-3703.

9. Chandan VS, Wang W. Pancreatic heterotopia in the gastric antrum. Arch Pathol Lab Med. 2004;128(1):111-112.

10. Kim JY, Lee JM, Kim KW, Park HS, Choi JY, Kim SH, Kim MA, et al. Ectopic pancreas: CT findings with emphasis on differentiation from small gastrointestinal stromal tumor and leiomyoma. Radiology. 2009;252(1):92100.

11. Ulrych J, Fryba V, Skalova H, Krska Z, Krechler T, Zogala D. Premalignant and malignant lesions of the heterotopic pancreas in the esophagus: a case report and review of the literature. J Gastrointestin Liver Dis. 2015;24(2):235-
239.

12. Sharma SP, Sohail SK, Makkawi S, Abdalla E. Heterotopic pancreatic tissue in the gallbladder. Saudi Med J. 2018;39(8):834-837.

13. Lee NK, Kim S, Kim GH, Jeon TY, Kim DH, Jang HJ, Park DY. Hypervascular subepithelial gastrointestinal masses: CT-pathologic correlation. Radiographics. 2010;30(7):1915-1934.

14. Von Heinrich H. Ein Beitragzur Histologie des sogenanntenakzessorischen Pankreas. Virchows Arch A Pathol Anat Histopathol. 1909;198:392-440.

15. Zhang Y, Sun X, Gold JS, Sun Q, Lv Y, Li Q, Huang Q. Heterotopic pancreas: a clinicopathological study of 184 cases from a single high-volume medical center in China. Hum Pathol. 2016;55:135-142.

16. Betzler A, Mees ST, Pump J, Scholch S, Zimmermann C, Aust DE, Weitz J, et al. Clinical impact of duodenal pancreatic heterotopia - Is there a need for surgical treatment? BMC Surg. 2017;17(1):53.

17. Eisenberger CF, Gocht A, Knoefel WT, Busch CB, Peiper M, Kutup A, Yekebas EF, et al. Heterotopic pancreasclinical presentation and pathology with review of the literature. Hepatogastroenterology. 2004;51(57):854-858.

18. Chen HL, Chang WH, Shih SC, Bair MJ, Lin SC. Changing pattern of ectopic pancreas: 22 years of experience in a medical center. J Formos Med Assoc. 2008;107(12):932936.

19. Li LM, Feng LY, Chen XH, Liang P, Li J, Gao JB. Gastric heterotopic pancreas and stromal tumors smaller than 3 $\mathrm{cm}$ in diameter: clinical and computed tomography findings. Cancer Imaging. 2018;18(1):26.

20. Persano G, Cantone N, Pani E, Ciardini E, Noccioli B. Heterotopic pancreas in the gastrointestinal tract in children: a single-center experience and a review of the literature. Ital J Pediatr. 2019;45(1):142.

21. Armstrong CP, King PM, Dixon JM, Macleod IB. The clinical significance of heterotopic pancreas in the gastrointestinal tract. Br J Surg. 1981;68(6):384-387.

22. Dolan RV, ReMine WH, Dockerty MB. The fate of heterotopic pancreatic tissue. A study of 212 cases. Arch Surg. 1974;109(6):762-765.

23. Lai EC, Tompkins RK. Heterotopic pancreas. Review of a 26 year experience. Am J Surg. 1986;151(6):697-700.

24. Shi HQ, Zhang QY, Teng HL, Chen JC. Heterotopic pancreas: report of 7 patients. Hepatobiliary Pancreat Dis Int. 2002;1(2):299-301.

25. Jun SY, Son D, Kim MJ, Kim SJ, An S, Park YS, Park SR, et al. Heterotopic pancreas of the gastrointestinal tract and associated precursor and cancerous lesions: systematic pathologic studies of 165 cases. Am J Surg Pathol. 2017;41(6):833-848. 